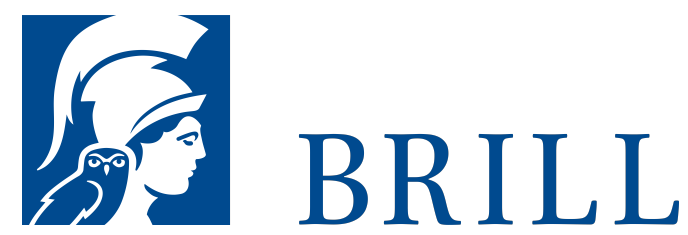

\title{
Soziale Pluralitäten
}

Zur Ontologie, Wissenschaftstheorie und Semantik des Klassifizierens und Gruppierens von Menschen in Gesellschaft und Humanwissenschaft

Author: Rico Hauswald

Eine soziale Pluralität liegt vor, wann immer wir mehrere Menschen als irgendwie zusammengehörig betrachten und auf sie als Vielheit Bezug nehmen. Das kann beispielsweise der Fall sein, weil diese Menschen bestimmte Gemeinsamkeiten aufweisen oder weil sie eine Gemeinschaft bilden. Einzelne Formen sozialer Pluralitäten werden in vielen philosophischen und wissenschaftlichen Teildisziplinen untersucht, etwa im Rahmen der wissenschaftsphilosophischen Debatte über das Vorkommen natürlicher Arten im Gegenstandsbereich der Humanwissenschaften, der sozialontologischen Diskussion zu kollektiver Intentionalität oder der Auseinandersetzung mit der von Ian Hacking propagierten Theorie interaktiver Arten. Bislang ist jedoch kein umfassender Versuch unternommen worden, eine Theorie sozialer Pluralitäten schlechthin zu entwickeln, in der Gemeinsamkeiten, Unterschiede und Wechselbeziehungen zwischen den einzelnen Pluralitätsformen und den diesen jeweils gewidmeten Debatten aufgezeigt werden. Dieses Buch stellt einen solchen Versuch dar. Soziale Pluralitäten werden auf drei Grundformen reduziert: Mengen, Klassen und Kollektive. Diese Formen werden untersucht hinsichtlich der ihnen zugrunde liegenden Ontologie, der Prinzipien ihrer wissenschaft lichen Erforschung sowie der Semantik der Begriffe, mit denen wir uns in wissenschaft lichen und außerwissenschaftlichen Kontexten auf sie beziehen.

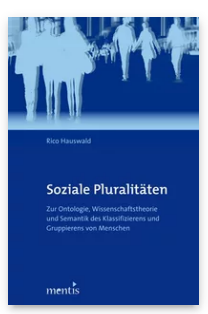

Pages: 279

Seiten

Language:

German

Subjects:

General,

Philosophy

Publisher: Brill | mentis

E-Book (PDF)

Released online:

19 Sep 2014

ISBN: 978-3-

95743-998-7

List price

Paperback

Publication date:

19 Sep 2014

ISBN: 978-3-

89785-417-8

List price 
For more information see brill.com

Order information: Order online at brill.com +44330 333 0049 | customerservices@brill.com Submission information: brill.com/authors

Titles published by Brill | Fink, Brill | mentis or Brill | Schöningh: +49(o)715413279216| brill@brocom.de 